\title{
A CONCEPTUAL FRAMEWORK TO APPLY FINANCIAL ENGINEERING AT THE ENTERPRISE
}

\author{
Viktor Zamlynskyi ${ }^{1}$, Anastasiia Zerkal ${ }^{2}$, Andrii Antonov ${ }^{3}$
}

\begin{abstract}
The development and continuous complication of financial instruments through the integration of technology and management methods lead to an increasing role of financial engineering to ensure the efficient activity of enterprises. The use offinancial engineering at the presentstage allows business entities to comprehensively solve the most pressing problems, from the liquidity crisis and to the lack of resources to implement long-term goals. In view of the fact, this direction of research has not yet received wide distribution in the domestic scientific literature. Thus, the definition of the conceptual foundations for the functioning of the financial engineering system in combination with the refinement of its essential characteristics is an urgent scientific task. The purpose of the article. The article aims to justify the conceptual provisions of financial engineering as an independent scientific and practical direction of economic research. Methodology. Methodological principles on which the study is based contain the application of a set of universal scientific methods and specific methods of scientific knowledge, including: the method of scientific abstraction in determining the characteristics of the innovative component of financial engineering; the method of system-structural analysis in justifying the diagnostic functions of the financial engineering of an enterprise, and the method of analysing time series when assessing the development of the options market in Ukraine. Value/originality. The article describes the essence of financial engineering. It is substantiated that financial engineering is to create innovations in the form of financial products, processes, technologies, and institutions in order to obtain financial benefits from their practical use in the activities of the enterprise. The fundamental difference between the concepts of "financial management"and"financial engineering"is disclosed. The characteristics and theoretical significance of financial engineering as independent scientific and practical areas of economic research are analysed. Modern approaches to the definition of objects, methods, information base, and the results of financial engineering are systematized. Financial engineering is considered as the process of designing, developing, and implementing innovative financial instruments. The characteristic of using financial engineering is given on the example of options trading. The features of the development of the options market in Ukraine are analysed. It was determined that the development of the domestic options market requires first of all the formation of practical skills in the use of derivative financial instruments by financial engineering methods.
\end{abstract}

Key words: management, financial system, financial engineering, diagnostics, organizational changes, improvement, liquidity.

JEL Classification: G11, G29, G39, H19

\section{Introduction}

In modern conditions, the main purpose of financial management is to maximize the market value of the enterprise. From the point of view of the income approach to business valuation, the market value is formed as a set of discounted cash flows calculated by intervals of the forecast period. These streams are formed as a result of the current investment and financial activity of the enterprise. In this regard, the enterprise has the task of managing financial resources, including the management of cash flows.

To solve this problem, financial engineering is used, which combines a set of methods and technologies that allow you to effectively manage finances in order to increase the value of the enterprise. Technologies that are used in the framework of financial engineering combine the financial subsystem of an enterprise and the financial instruments of the capital market. This allows the

\footnotetext{
Corresponding author:

${ }^{1}$ Odesa National Polytechnic University, Ukraine.

E-mail: zam.agrariy@gmail.com

${ }^{2}$ Classic Private University, Ukraine.

E-mail: zcci@i.ua

${ }^{3}$ Zhytomyr State Technological University, Ukraine.

E-mail: d-38-053-03@ukr.net
} 
company to solve a number of financial problems: from a liquidity crisis (lack of working capital) to an investment crisis (lack of financial resources for the implementation of long-term development programs). One of the elements of the redistribution of risks, profitability, liquidity is financial engineering. It allows enterprises to get a number of advantages when correctly applied: increase the value of the company, increase profits, ensure financial stability, balance cash flows, and the like. For the national economy, financial engineering is a new element that economic entities rarely use in their activities. Positive foreign experience of its use requires from state authorities, domestic enterprises, and financial intermediaries to more actively master the tools of financial engineering, which will stimulate the development of the Ukrainian economy in general and economic entities in particular.

In the European Union, the basic rules for the implementation of financial engineering are governed by the articles of Regulation (EC) No. 1083/2006, No. 1080/2006, No. 1081/2006, and No. 1828/2006 (as amended by Commission Regulation (EU) No. 1236/2011), which induces financial engineering tools for enterprises (venture capital funds, guarantee funds and credit funds etc.).

In Ukraine, the process of organizing the market for financial instruments is still ongoing and, unfortunately, there is an incomplete legislative base of regulation implementation of financial engineering, as in leading countries of the world. Currently, the implementation of financial engineering is regulated by the Tax Code of Ukraine, the Civil Code of Ukraine, the Law of Ukraine "On Securities and Stock Market", the Law of Ukraine "On State Regulation of the Securities Market in Ukraine" and other regulatory documents.

\section{Analysis of recent research and publications}

The scientific works are devoted to the study of the features of the financial engineering system, including the goals, subjects, object, principles, and tools of financial engineering. The research of individual elements of financial engineering by scientists (Kim, 1993; Marshal, Bansal, 1998; Kraskevich., Selivanova, 2016; Mashliy, Laba, 2016) analysed the concept of "financial engineering" using a structural approach, which gave it the opportunity to come to the conclusion that modern scientific literature does not contain a complete definition of this concept, especially in defining the purpose and methodology of introducing financial engineering in the financial activities of economic systems. In this regard, the definition of the conceptual foundations of the functioning of the financial engineering system in combination with the refinement of its essential characteristics is an urgent scientific task.

Hammer M. and Champy J. (Hammer, Champy, 1993) believe that the key question of reengineering consists of four key elements:
1. A focus on fundamentals. Addressing the issue of precisely what the corporation does, why is it done in a present way, and what are the tacit rules and assumptions embedded in present practices. Reengineering ignores "what is" and concentrates on "what should be."

2. A radical redesign element. Reengineering is about reinventing the business - not making superficial changes or marginal enhancements to the old ways of doing things.

3. The potential for dramatic results. Reengineering leads to quantum leaps in performance - not incremental improvements.

4. A business process orientation. Reengineering evolves around business processes - not tasks, job descriptions, people or structures. A business process takes an input or inputs and generates an output which is of value to the customer. A business process only works if it generates added value, not an internal activity.

Fortunately, innovations in telecommunications, information technology, and financial engineering offer the practical prospect for multiple channels for the financing of economic growth. Multiple channels for capital raising are a good idea in terms of greater assurance of supply at competitive prices. They also offer the prospective benefits of competition to be the best one in a given environment at a given point in time (Merton, Bodie, 2005).

The purpose of the article is to substantiate the conceptual foundations of financial engineering as an independent scientific and practical direction of economic research.

\section{Conceptual foundations of financial engineering}

Financial engineering should be considered as a set of economic relations that have monetary characteristics and provide functional actions for making, implementing, and optimizing financial and organizational decisions in the course of reforming, current functioning, and development of an enterprise based on innovative elements. It seems appropriate to analyse the relationship between financial engineering and financial management since innovative development is one of the goals of financial management, with the result that financial management methods can be used as financial engineering methods.

For a clearer definition of the relationship and fundamental differences between financial management and financial engineering, a comparative description of their components and elements should be made. Both concepts involve the use of an object management system. The objectives of financial management are divided into tactical and strategic. The objectives of financial engineering can be formulated in a similar way since they are considered depending on the result 
to which the application of financial engineering is directed (Kraskevich, Selivanova, 2016).

Differences in financial engineering and financial management are manifested in the fact that financial management is essentially a continuous process, the goals of which are interconnected and are adjusted to reflect the situation and the result obtained earlier. The goals of financial engineering are final, clearly defined, and may not be related. In this case, the whole process is aimed at achieving one goal, as a result of which the need for financial engineering, as in a particular product, ends. As a result, such phenomena as risks and profitability cannot be an object of financial engineering since they are manageable and integral components of the enterprise's activity. It is financial management that should be focused on these factors, which can be transformed according to their qualitative characteristics using the tools of financial engineering.

Consequently, scientific and practical interest represents the main fundamental positions inherent in financial engineering. Consideration of the principles of construction and operation of financial engineering involves consideration of the leading provisions of its operation. The construction of financial engineering on the basic provisions of finance makes it possible to apply the scientific approach of transforming the functional positions of finance in the fundamental provisions of financial engineering. The relevance of the application of financial engineering is manifested in the scientific and practical terms, in the sectoral and subjective scale. The functional purpose of finance in the formation of monetary funds is becoming a fundamental position of financial engineering as a technologically instrumental basis for making financial decisions in the field of providing the means of the operation and development of an enterprise.

The theoretical significance of financial engineering is implemented through its isolation as an independent scientific and practical research direction. This requires the formulation of the goal of financial engineering as a complex criterion for making financial decisions of an enterprise. The goal of financial engineering is to see the integration of the enterprise's activities, aimed at improving the quality of strategic and tactical financial decisions in all areas of business, is achieved by concentrating efforts on the priority areas of the company's activities. This target emphasizes the longterm period of the enterprise, points to ways to increase financial results, takes into account the interests of the owners. This takes into account the aspect of uncertainty and risk (probability of loss) when making and implementing financial decisions.

Information base of financial engineering should be updated financial and management reporting of the enterprise. Sectoral and regional analytical materials can be used. Reliability must unambiguously be ensured. However, the relative indicators of the financial condition of the company cannot be the result of financial engineering since they are calculated and their value depends on a number of factors (Kraskevich, Selivanova, 2016).

Thus, the engineering process should be directed to influence precisely these initial factors, and the efficiency of engineering use, in turn, can be measured using the values of these relative indicators. In addition, it should also be noted that the reasoning of economists as a starting point is the driving force for changes in the direction that is determined by the financial decision.

The financial decision in financial engineering acts as a result of the economic actions of managers and specialists of the enterprise on the basis of a sample of several options. It should be borne in mind that the above-mentioned persons should be guided by the principles of expediency and rationality, take into account the available funds, internal and external factors affecting the operation of a particular company. In the course of the formation and implementation of a financial decision in financial engineering, it goes through several stages. First, there is an operational or problem situation that requires a financial decision. Then the database is collected and processed for the next stage - the preparation and development of a financial solution. Preparatory work determines the financial goal. A program of measures to implement a financial decision is consistently drawn up, a selection of financial instruments, levers, and management techniques is carried out.

Mainly, scientists identify the methods of financial engineering as the creation of a fundamentally new method or a combination of existing methods to obtain new properties. However, creation and combination are only the names of the processes that are achieved with the help of certain tools and are based on the use of a number of mathematical, statistical, and computational methods. Given this, it is advisable to distinguish the following groups of financial engineering methods in accordance with the expected result:

- mathematical, statistical and other quantitative methods: in the design, development, distribution, association - to achieve a fundamentally new financial situation; when modified, combined - to change certain features of the initial financial situation of the enterprise; - financial management methods - to reduce risk and achieve a certain level of enterprise profits (Kraskevich, Selivanova, 2016).

An important step in financial engineering is also determining the result of its use. To do this, it is advisable to divide the expected result from the application of financial engineering into two main parts:

- a fundamentally new, innovative financial situation or product that is qualitatively different from the initial one and before which certain tools were applied;

- a financial situation or a product that does not have essential differences from the original, but some properties of which are more favourable for the subject of the application of financial engineering. 
From the point of view of the economic content of the result, it is possible to single out the following elements: an innovative product, a new organizational structure for financial management, relative indicators of the financial condition of an enterprise (profitability, liquidity etc.).

Thus, the product of (financial) engineering is innovation. Innovation is "investment in innovations" in the form of the achieved results from the development of a new process, product or service in practice. Innovation is some kind of innovation that has not been encountered before: a new industrial design, an intellectual discovery, an invention, a method for meeting the needs of society, and that sort of thing. However, innovation should be viewed as the ultimate achievement of innovation, which is embodied in a new or improved product, has become competitive in the market; in a new or improved technical and technological process, found practical use in the economic activity.

In summary, conceptually financial engineering can be defined as the process of creating innovations in the field of finance. However, this characteristic of financial engineering does not fully reflect its content but gives only a general idea of its essence. Therefore, special attention should be paid to the analysis of the works of domestic and foreign authors on this topic to summarize the existing conceptual approaches to the functioning of the financial engineering system.

In our opinion, one of the most complete interpretations of financial engineering is the definition, which includes projection, the development and introduction of innovations or the search and application of new approaches to solving financial problems using already known innovative financial instruments and technologies in order to achieve specific financial goals by enterprises. On the other hand, a number of researchers emphasize the practical side of financial engineering as an activity. They reveal the mechanism for creating financial innovations, which is presented either in the form of combining and decomposing existing financial instruments or in the form of modifying the inherent characteristics of existing financial instruments (Marshal, Bansal, 1998).

Expanding the scope of application of financial engineering, Kim T. (1993) defines it as "unpredictable changes in the form of a new financial product, payment system or organizational structure for the provision of new financial services." Thus, changes can be expressed in the form of a new financial product, payment system or organizational structure. At the same time, it is very important to point out their diversity and originality, which determines their innovative nature (Hammer, Champy, 1993). This allows us to talk about innovations not only in the field of financial instruments but also about institutional innovations in the financial market. This view reflects the current level of development of financial engineering and its scope the most.
At the same time, an alternative approach to interpreting the conceptual foundations of financial engineering is extremely common. It is based on the assumption that financial engineering is closely related to risk management. This position is quite reasonable, especially given the fact that the rapid growth of risks in the implementation of the activities of companies has become one of the key factors for the emergence and development of financial engineering. At the same time, risk management, including their minimization, is one of the possible ultimate goals of developing and implementing financial innovations, which is not the only one and not always the main target, which, however, does not detract from its significance. It is widely known that risk is a payoff rate. This statement can be formulated differently: the corresponding return is the reward of the investor for taking the appropriate level of risk. Thus, it can be argued that risk management involves the search for optimal ratios in the "risk return” plane (Gerasimovich, 2017).

The above makes financial engineering a leading mechanism for financial diagnostics at the current stage because financial engineering is the desire to reduce risk and develop new technology to get more profit. Therefore, risk reduction is either an intermediate goal or a tool for making more profit.

\section{Financial engineering and innovative financial instruments - the potential for solving modern financial problems}

The result of reducing the level of risk due to the diagnosis of the financial state of engineering methods is the most stable operational and financial activity of the company, which in the long run uniquely increases the income received. The above clearly reflects the purpose of financial engineering as a type of activity and indicates the innovative nature of this activity.

Separately, domestic scientists cite warnings about the use of engineering as a mechanism for diagnosing future threats to companies since financial instruments developed artificially, thanks to their design by financial engineering methods, have already become one of the significant factors that provoked the global financial and economic crisis of 2008-2009. Therefore, it should be remembered that financial engineering is not a panacea in this area, and ensuring financial security from threats associated with the proliferation of financial engineering products should be based on a system of preventive diagnostics of threats and risks of the latest financial instruments.

The following common approach to determining the conceptual foundations of financial engineering is focused on solving certain financial problems. It proceeds from the ambivalent understanding of financial engineering, the use of investment technology to solve financial problems, as well as the use of financial 
instruments to transform the existing financial situation into another that has more preferable features. Such an interpretation of financial engineering focuses on its innovative nature. Solving financial problems and transforming the existing financial situation into another one, which is desirable, speaks of obtaining certain benefits from the implementation of this process. This is an extremely important feature that is rarely reflected in the analysis of financial engineering. It is the achievement of the situation with more desirable properties than the existing ones that, in our opinion, is the main goal of financial engineering. Otherwise, innovation itself loses its expediency.

Thus, the use of financial engineering has the potential to ensure the emergence and rapid development of

Table 1

Dynamics of the volume of registered issues of options in Ukraine in 2014-2018

\begin{tabular}{|l|c|c|c|c|c|}
\hline \multicolumn{1}{|c|}{ Indicators } & 2014 & 2015 & 2016 & 2017 & $\begin{array}{c}\text { January- } \\
\text { October } \\
2018\end{array}$ \\
\hline $\begin{array}{l}\text { Options, million } \\
\text { UAH }\end{array}$ & 1,3 & 0,2 & 198,9 & 32,5 & 55,0 \\
\hline $\begin{array}{l}\text { Issued option } \\
\text { certificates, pieces }\end{array}$ & 17 & 16 & 9 & 2 & 1 \\
\hline $\begin{array}{l}\text { Total securities, } \\
\text { billion UAH }\end{array}$ & 217,3 & 155,8 & 221,2 & 353,7 & 44,8 \\
\hline Option share, \% & 0,0006 & 0,0001 & 0,0899 & 0,0092 & 0,1228 \\
\hline
\end{tabular}

Source: compiled by the authors according to the National Securities and Stock Market Commission a number of financial instruments that have not yet been properly disseminated and used by enterprises in developing countries. For example, let us take the Ukrainian market of such derivative financial instruments as options, which are widely used in the global financial markets when carrying out investment operations, but still have a tiny share in the domestic stock market (Table 1).

During 2014-2018, the most valuable options' issue volumes on the Ukrainian stock market were observed in 2016 when they reached 198,900,000 UAH. However, even their share in the total volume of securities did not exceed $0.09 \%$. The largest share of options is observed in January-October 2018 and accounts for $0.12 \%$, although its level is primarily due to the rapid decline in the stock market of Ukraine as a whole. During the aforementioned period, only one issue of option certificates worth 55.0 million UAH was made, whereas the total issue of securities amounted to 448 billion UAH (Analytical data on stock market development, 2018). To exit the options market of Ukraine from a rudimentary state, along with an increase in the investment attractiveness of the economy and raising capital, sufficiently deep knowledge and skills in the use of derivative financial instruments are needed (Mashliy, Laba, 2016). Therefore, financial engineering as a mechanism for optimizing option contracts is of particular importance for the wide distribution of this financial instrument in the investment activities of domestic enterprises. From the position of financial engineering, enterprises should take into account the relationship of investment

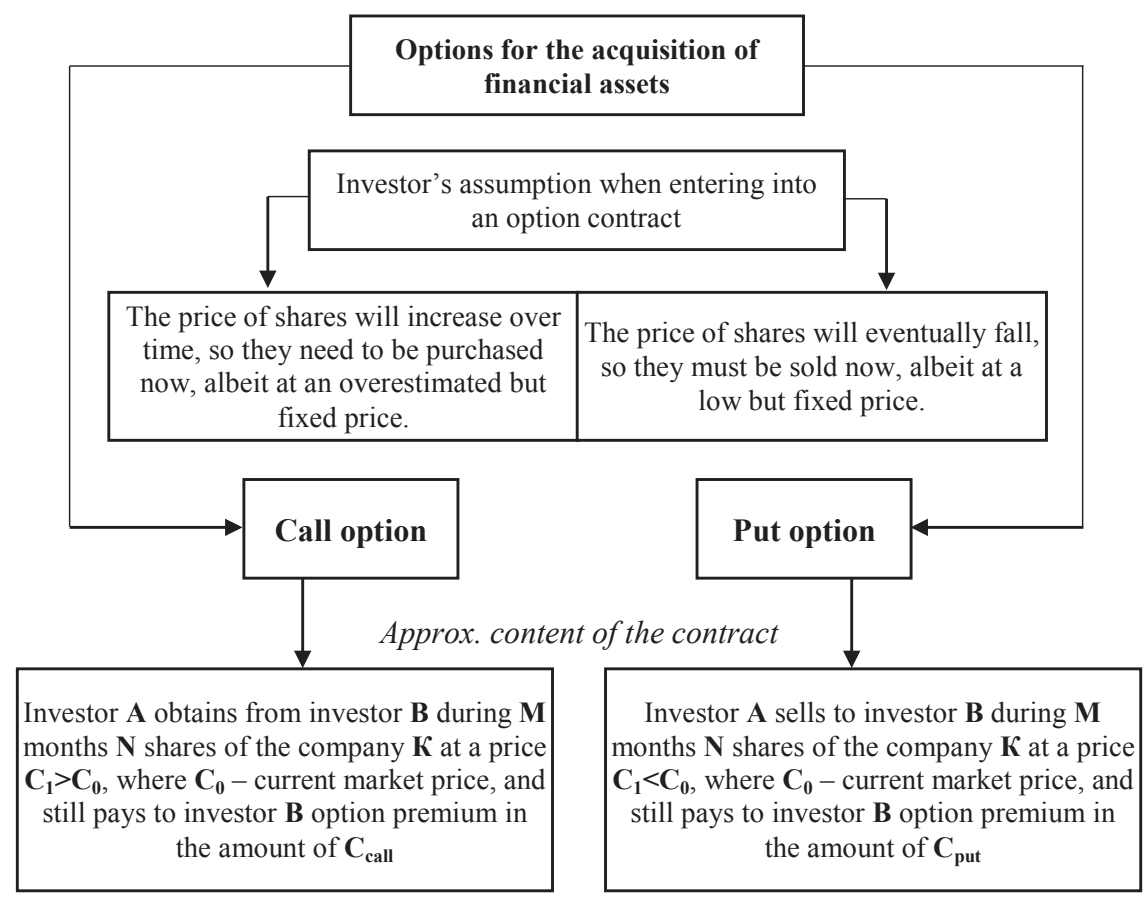

Figure. 1. Conceptual content of call and put options

Source: built by the authors 
and the stages of the lifecycle of an enterprise since the actual formation of financial resources is possible at the stage of stability but, for the purpose of investment, is carried out at all stages of the enterprise lifecycle (Koval, Prymush, Popova, 2017). Consider the technology of financial transactions using options to buy and sell company shares. Figure 1 presents a conceptual model of put options and a call option.

Suppose that at the moment (the SQ situation, meaning "status quo"), shares of company $K$ are being sold $\$ 40$ for each. Investor A wants to acquire 100 shares of company $K$ since it assumes that shares will grow over time. However, potential investor $A$ currently has not $\$ 4,000$ to buy these shares on the exchange, so he wants to offer investor $\mathrm{B}$ an agreement: agree to sell him 100 shares of company $K$ for $\$ 45$ (which now cost only $\$ 40$ ), but in any time point within 3 months. In order to fulfil his intention, investor $A$ needs to interest investor $B$, therefore, he suggests buying a call option from him and for this, he appoints the latter an option premium of $\$ 2$ per share, that is, $\$ 200$. Investor $A$ can borrow this amount.

Investor $B$ does not consider that the shares for the period indicated by investor $A$ will rise in price above $\$ 40$, but there is a similar risk. Therefore, if investor B agrees to the risk of a reward of $\$ 200$ offered to him, then potential investor $A$ will buy a contract with an option call at $\$ 200$, for which he is guaranteed to be able to purchase the 100 shares he needs from investor $\mathrm{B}$ for 3 months for $\$ 4,500$.

Let us consider the possible outcomes of a contract with a call option. For example, the shares of company $\mathrm{K}$ in three months began to be sold at a price of $\$ 50$ per share. This means direct losses in the price of $\$ 500$ for side $B$ since the investor will have to buy 100 shares of company $K$ in the market at the current price of $\$ 50$, paying $\$ 5,000$ for them, and sell them to investor $A$ at the price of $\$ 45$. That is, he will receive from the investor only $\$ 4,500$ for them. However, shares may fall in price in three months and cost, for example, $\$ 35$ per share. In this case, investor $A$ will have to execute the contract on unfavourable conditions and pay $\$ 4,500$ to investor $B$ for purchasing 100 shares of company $K$ from him (although he could pay for them only $\$ 3,500$ in the market). Thus, a contract with a call option costs money for investor $A$, that is, it has a price (in our case, \$200).

Theprice of theoption dependsonthelevelofuncertainty of the current situation in relation to the future. However, the significant impact on the size of the option premium has also how the participants of this risky agreement with the securities estimate the prospect themselves. Because of this feature of options, the importance of using financial engineering as a mechanism to ensure an optimal balance between risk and profitability increases. In particular, in order to mitigate the consequences of an option agreement, the parties often specifically make it possible to liquidate a contract before it expires or to freely resell its part of the contract to third parties.

\section{Application of financial engineering using option contracts example}

Let us consider in more detail the mechanism of financial engineering under the condition that when making the option, the parties have provided the opportunity to refuse contractual obligations in favour of the third parties. Let, for example, a month after the conclusion of a contract, the situation changed (we denote it as SQ1), the market price increased by $\$ 10$ and, as a result, amounted to $C 1=\$ 50$. If current information is refined, investor $B$ can decide based on two possible alternatives. The first alternative is to buy out a contract from investor $\mathrm{A}$ at this price and close this contract. Suppose investor B offered, and investor $A$ accepted the offer to close the contract, provided that he received from investor $B$ at $\$ 5$ per share. If the parties agree, the results of such an operation will be: $Y a=-200+500=300 ; Y=200-500=-300$. The second alternative to investor $B$ is to transfer positions on the contract to a third party, paying it for taking on all the obligations. In this case, investor B acts as the "first" seller of the option, therefore in this alternative, it is more convenient to call him B1, and the third person as the "second" seller B2. Suppose that investor B2 agrees to repurchase the call option from investor $B 1$ if he pays him $\$ 5$ per share, that is, $\$ 500$. In this case, the contract will be supplemented by the condition that investor B2 becomes the seller of the option, and the results of these financial operations will be: $Y_{A}=-200$; $Y_{B 1}=200-500=-300 ; Y_{B 2}=500$.

However, investor A may also refuse to execute the contract with the option number over time. To do this, he needs to find the "second" potential buyer of shares $A 2$, who wants for some fee, for example, $\$ 6$ per share, that is, for $\$ 600$, to buy a contract of "first" potential buyer, $A 1$. In this case, the contract will be supplemented by the condition that the buyer of the option becomes investor $\mathrm{A} 2$, and the results of the financial transaction will be: $Y_{A 1}=-200+600=400 ; Y_{A 2}=-600 ; Y_{B 1}=200$.

Finally, each of the participants in the option contract can find a third person for himself. In this case, both "first" investors will be excluded from the contract, and their places will be "second". As a result, buying and selling options for them under the above-mentioned conditions of sale will lead to the following results $Y_{A 2}=-600 ; Y_{B 2}=500$.

Table 2 presents the results of the application of financial engineering while implementing an option contract for different scenarios.

Summarizing the conceptual foundations and practical mechanisms for the application of financial engineering presented in the article using the example of option contracts, we note that financial engineering is largely a creative process of creating financial innovations in the form of financial products, processes, technologies, and institutions in order to obtain financial 
Table 2

Impact of financial engineering on the results of the implementation of the option contract

\begin{tabular}{|c|c|c|}
\hline $\begin{array}{c}\text { Strategies of investors A } \\
\text { and B }\end{array}$ & $\begin{array}{l}\text { Continuation } \\
\text { of the execution } \\
\text { of the contract }\end{array}$ & $\begin{array}{c}\text { Transfer of your } \\
\text { positions } \\
\text { on the contract } \\
\text { to investor B2 }\end{array}$ \\
\hline $\begin{array}{l}\text { Continuation of the } \\
\text { execution of the contract }\end{array}$ & $\begin{array}{l}Y_{\mathrm{A} 1}=-200 \\
Y_{\mathrm{B} 1}=200\end{array}$ & $\begin{array}{l}Y_{\mathrm{A} 1}=-200 ; \\
Y_{\mathrm{B} 1}=-300 ; \\
Y_{\mathrm{B} 2}=500 ;\end{array}$ \\
\hline $\begin{array}{l}\text { Transfer of your positions on } \\
\text { the contract to investor A2 }\end{array}$ & $\begin{array}{c}Y_{\mathrm{A} 1}=400 ; \\
Y_{\mathrm{A} 2}=-600 ; \\
Y_{\mathrm{B} 1}=200\end{array}$ & $\begin{array}{l}Y_{\mathrm{A} 2}=-600 \\
Y_{\mathrm{B} 2}=500\end{array}$ \\
\hline
\end{tabular}

Source: built by the authors

benefits from their practical use in the activities of the enterprise. A deeper understanding of the content of financial engineering requires an analysis of the causes of its appearance and development factors, which leads to the prospect of further research in this direction.

\section{Conclusions}

The result of financial engineering is financial innovation in the form of a new financial product, new technology or process, new financial institutions. Financial products should be understood as both financial instruments and services in the field of finance. The key task of financial engineering is to transform the existing financial enterprise situation into another, more desirable for it. In other words, its main goal is to obtain financial benefits, primarily due to the reduction of risk and the achievement of a certain level of enterprise profitability. In the process of financial engineering, there is a problem situation, data are being collected and processed, a program of relevant measures is being consistently put together and implemented.
The theoretical significance of financial engineering is realized through its allocation as an independent scientific and practical direction of research with its own purpose, target directions and methods of realization of financial decisions. An important stage in the application of financial engineering in the enterprise's activity is to determine the expected result of its application, which acquires forms of innovative products in the form of new organizational structures of financial management, system approaches to the calculation of indicators of the financial state of the enterprise etc.

An alternative approach to defining the conceptual foundations of financial engineering is to focus on solving certain financial problems. This approach proceeds from the ambivalent understanding of financial engineering, the use of investment technology to solve financial problems, as well as the use of financial instruments to transform the existing financial situation into another, a more favourable one. This is an extremely important property that is rarely reflected in the analysis of financial engineering because achieving a situation with more desirable properties than the existing ones is the main goal of financial engineering, without which any innovation activity loses its feasibility.

Analysis of the development of the domestic options market showed that financial engineering as a mechanism for optimizing option contracts is of particular importance for the wide distribution of this financial instrument in the investment activities of economic entities of Ukraine. The parties' use of option contracts of various financial engineering strategies makes it possible to optimize the risks of options transactions, ensuring the optimal ratio between the levels of their riskiness and profitability.

\section{References:}

Analytical data on stock market development (2018). National securities and stock market commission. Retrieved from: http://www.ssmsc.gov.ua/fund/analytics

Gerasimovich, I. A. (2017). Mechanisms and tools of accounting and financial engineering in the management of the enterprise. Accounting and finance, 1(75), 26-32. (in Ukrainian)

Hammer, M., Champy, J. (1993). Reengineering the corporation: a manifesto for business revolution. New York: Harper Collins.

Kim, T. (1993). International money and banking. Washington: Routledge.

Koval, V., Prymush, Y., Popova, V. (2017). The influence of the enterprise life cycle on the efficiency of investment. Baltic Journal of Economic Studies, 3(5), 183-187. doi: 10.30525/2256-0742/2017-3-5-183-187.

Kraskevich, V. Ye., Selivanova A. V. (2016). Financial engineering as an innovation tool in investment projects. Mathematical machines and systems, 1,71-78. (in Ukrainian)

Marshal, J. F., Bansal, V. K. (1998). Financial engineering: a complete guide to financial innovation. New-York Institute of Finance.

Mashliy, G. B., Laba, I. Z. (2016). Status and prospects of the options market in Ukraine. Proceedings of the XIX International scientific-practical conference: Socio-economic development in the conditions of globalization. Kiev: Scientific-publishing center "Laboratory of thought". (in Ukrainian)

Merton, R., Bodie, Z. (2005). Design of financial systems: towards s synthesis of function and structure. Journal of investment management, 3(1), 1-23. 